\title{
Progresso da ramulose em campo a partir de sementes de algodoeiro inoculadas com Colletotrichum gossypii var. cephalosporioides
}

\author{
Dejânia V. de Araújo ${ }^{1}$, Gian B. Zambenedetti ${ }^{1}$, Rivanildo Dallacort ${ }^{1}$, Vírgínia H. de Azevedo² \& Janile \\ T. Mainardi ${ }^{1}$
}

${ }^{1}$ Departamento de Agronomia, Universidade do Estado de Mato Grosso, 78300-000, Tangará da Serra, MT, Brasil; ${ }^{2}$ Faculdade de Agronomia e Medicina Veterinária, Universidade Federal de Mato Grosso, 78060-900, Cuiabá, MT, Brasil

Autor para correspondência: Dejânia V. de Araújo, e-mail: dejania@unemat.br

\begin{abstract}
RESUMO
Objetivou-se avaliar a severidade e o progresso da ramulose no campo a partir de diferentes tempos de exposição das sementes de algodoeiro ao fungo Colletotrichum gossypii var. cephalosporioides. O experimento foi conduzido com cinco tratamentos e quatro repetições. Os tratamentos foram compostos por parcelas contendo 5\% de sementes inoculadas nos tempos $0,36,72,96$ e $108 \mathrm{~h}$ de exposição ao patógeno. As avaliações foram feitas dos 46 dias até os 111 dias após a semeadura e os dados transformados para área abaixo da curva de progresso da incidência (AACPI) e da severidade (AACPS) da doença. Observou-se que a incidência de C. gossypii var. cephalosporioides cresceu de acordo com o aumento do tempo de exposição das sementes ao patógeno, chegando a $99 \%$ de incidência no tempo 108 h. Por outro lado, houve redução na germinação das sementes conforme o aumento no tempo de exposição, de $99 \%$, no tempo 36 horas, para 92\%, no tempo 108 horas. A AACPI e a AACPS da doença foram maiores com o aumento do tempo de exposição das sementes ao patógeno, observando-se o progresso da incidência $(93,1 \%)$ e da severidade $(42,5 \%)$ no maior tempo de exposição das sementes $(108 \mathrm{~h})$ em relação à testemunha.
\end{abstract}

Palavras-chave: Gossypium hirsutum, inoculação de sementes, sanidade de sementes.

\begin{abstract}
Progress of cotton ramulosis in the field after disease establishment through inoculation of seeds with Colletotrichum gossypii var. cephalosporioides

The objective of this study was to evaluate the severity and the progress of ramulosis in the field after disease establishment through inoculation of cotton seeds with Colletotrichum gossypii var. cephalosporioides. The assay was carried out with five treatments and was replicated four times. The treatments consisted of plots with $5 \%$ of infected seeds that were inoculated through periods of exposure of seeds to the pathogen of 0,36, 72, 96 and $108 \mathrm{~h}$. Evaluations were made from 46 to 111 days after sowing and the data were transformed to area under the disease incidence progress curve (AUDPCI) and severity (AUDPCS). The incidence of ramulosis increased with increasing length of exposition of the seeds to the pathogen, reaching $99 \%$ of incidence at $108 \mathrm{~h}$. On the other hand, a reduction in the percentage of seed germination was observed when the exposition time increased. Seed germination dropped from $99 \%$ at $36 \mathrm{~h}$ to $92 \%$ at $108 \mathrm{~h}$. The AUDIPC and AUDSPC were influenced by the length of seed exposition to the pathogen. The higher progress of the incidence (93.1\%) and of the severity (42.5\%) occurred at $108 \mathrm{~h}$.
\end{abstract}

Key words: Gossypium hirsutum, seed health, seed inoculation.

\section{INTRODUÇÃO}

O Brasil está entre os maiores produtores de algodão (Gossipium hirsutum L.) do mundo. Assim como as demais culturas exploradas comercialmente, a do algodoeiro está sujeita à incidência de um elevado número de doenças, cujos patógenos são, em sua maioria, transportados e/ou transmitidos por sementes. Por meio dessa via, inúmeros patógenos de importância econômica podem ser disseminados a longas distâncias e causar prejuízos consideráveis, dependendo das condições ambientais e de outros fatores que favorecem o desenvolvimento das doenças (Pizzinato et al., 1991; Machado et al., 2004).

Patógenos associados às sementes podem reduzir a germinação e o vigor, além de contribuir para a deterioração de sementes durante o período de armazenamento. Sementes infectadas podem introduzir patógenos em novas áreas, bem como aumentar o inóculo em lavouras já estabelecidas. Se o inóculo primário, transportado via semente, encontrar ambiente favorável e o hospedeiro for suscetível, focos iniciais de infecção podem ser estabelecidos. A partir daí poderá ocorrer o progresso da doença no espaço e no tempo, a partir do inóculo secundário produzido nas lesões 
Progresso da ramulose em campo a partir de sementes de algodoeiro inoculadas...

das plantas infectadas (Campbell \& Madden, 1990; Tanaka $\&$ Menten, 1992; Alves et al., 2006).

Entre os patógenos de importância econômica para o algodoeiro, o fungo Colletotrichum gossypii South var. cephalosporioides A.S. Costa é transmitido tanto externa quanto internamente pelas sementes, que são o veículo de disseminação mais eficiente. Dessa forma, o patógeno pode ser transportado em curtas e longas distâncias e pode ser introduzido em novas áreas; além disso, a disseminação do patógeno pelas sementes contribui de forma eficiente para a distribuição de focos iniciais da doença na lavoura (Campbell \& Madden, 1990; Tanaka \& Menten, 1992; Alves et al., 2006). O fungo C. gossypii var. cephalosporioides é o agente etiológico da ramulose do algodoeiro. Esta doença interfere no desenvolvimento apical da planta, estimulando o brotamento de ramos laterais e comprometendo a produção (Tanaka \& Menten, 1992; Santos et al., 1994).

Estudar o progresso da doença, a partir da fonte de inóculo, possibilita conhecer a dinâmica da interação entre o patógeno e o hospedeiro, contribuindo assim para o manejo adequado da doença e o consequente aumento da produtividade da cultura. Além disso, o resultado dessas observações pode auxiliar no estabelecimento de padrões de tolerância para patógenos associados às sementes (Bergamin Filho et al., 2004; Alves et al., 2006; Araújo et al., 2006b; Araújo et al., 2009).

Em estudos com C. gossypii var. cephalosporioides via sementes inoculadas observou-se a transmissibilidade do patógeno, tanto da planta para a semente quanto da semente para a planta, em condições de campo no estado de Minas Gerais (Araújo et al., 2006b). Contudo, para a determinação de padrões de tolerância de um determinado patógeno em sementes, é necessário investigar o comportamento do patógeno e do hospedeiro, em condições em que o algodoeiro é cultivado em larga escala. Assim, o objetivo deste trabalho foi avaliar o progresso da ramulose do algodoeiro no campo, no estado de Mato Grosso, a partir de sementes inoculadas com C. gossypii var. cephalosporioides.

\section{MATERIAL E MÉTODOS}

\section{Área experimental e condução do experimento}

$\mathrm{O}$ experimento foi instalado na área experimental da Universidade do Estado de Mato Grosso, Campus de Tangará da Serra, geograficamente localizada a 14038'55" de latitude Sul e $57^{\circ} 25^{\prime} 52^{\prime}$ " de longitude Oeste, com altitude de $321,5 \mathrm{~m}$ e Latossolo Vermelho Distroférrico de textura média (Embrapa, 1999).

Utilizou-se o delineamento em blocos casualizados, com cinco tratamentos e quatro repetições, sendo a parcela experimental constituída por quatro linhas de $5,0 \mathrm{~m}$ de comprimento, considerando-se como área útil, as duas linhas centrais. $O$ espaçamento utilizado foi de $0,90 \mathrm{~m}$ entre linhas e a densidade de semeadura foi de 11 sementes por metro linear, sendo a distância entre os tratamentos dentro do bloco de 1,0 m e entre blocos de 2,0 $\mathrm{m}$.
Os tratamentos testados foram os tempos de exposição das sementes ao fungo $C$. gossypii. var. cephalosporioides $(0,36,72,96$ e $108 \mathrm{~h})$, sendo semeados, em cada parcela, $5 \%$ de sementes inoculadas por tempo de exposição. A quantidade de sementes inoculadas (5\%) adicionada na parcela foi calculada com base na densidade de semeadura. $\mathrm{O}$ tratamento $0 \mathrm{~h}$ foi considerado a testemunha sem sementes inoculadas. Os tratos culturais, como capinas e controle de pragas, foram realizados de acordo com a necessidade da cultura.

\section{Inoculação das sementes de algodoeiro}

Foram utilizadas sementes da variedade FMT 701, fornecidas pela Fundação Mato Grosso. As sementes foram analisadas quanto à sanidade e à germinação inicial. Para a sanidade foi utilizado o teste de papel de filtro (Neergaard, 1979), modificado pela adição de 2,4-D e ágar (2 g/L). Em placas de Petri de $15 \mathrm{~cm}$ de diâmetro foram acondicionadas 25 sementes, totalizando 200 sementes. Após sete dias de incubação em temperatura de $24 \pm 2^{\circ} \mathrm{C}$ avaliou-se a porcentagem de ocorrência de fungos nas sementes. O teste de germinação foi realizado pelo método de rolo de papel germitest umedecido com água destilada e o resultado foi dado em porcentagem de plântulas normais (Brasil, 2009). Os rolos de papel foram mantidos em germinador em temperatura de $25 \pm 2^{\circ} \mathrm{C}$ por sete dias.

Após os testes iniciais de sanidade e germinação, as sementes foram inoculadas com o patógeno pelo método de restrição hídrica (Machado et al., 2004, 2007). Utilizouse um isolado de C. gossypii. var. cephalosporioides. A metodologia constou da adição de $1,0 \mathrm{~mL}$ da suspensão de conídios do patógeno, na concentração de $10^{6}$ conídios/ $\mathrm{mL}$, em bandejas plásticas contendo manitol $(46,3 \mathrm{~g} / \mathrm{L})$ em meio BDA, com potencial hídrico ajustado para -1 $\mathrm{MPa}$, segundo cálculo feito com auxílio do software SPPM (Michel \& Radcliffe, 1995). As bandejas foram incubadas em temperatura de $25 \pm 2^{\circ} \mathrm{C}$ e fotoperíodo de 12 $\mathrm{h}$ por três dias, para o completo crescimento do patógeno. Sementes de algodão foram desinfestadas com hipoclorito de sódio $2 \%$ por $30 \mathrm{~s}$ e foram colocadas em contato com o patógeno e levadas novamente para BOD, nas mesmas condições descritas, sendo retiradas após 36, 72, 96 e 108 $\mathrm{h}$ de exposição e secas em ambiente por $24 \mathrm{~h}$. As sementes utilizadas como testemunha $(0 \mathrm{~h})$ foram submetidas apenas à assepsia com hipoclorito de sódio por um minuto. Após a inoculação foram realizados novamente os testes de sanidade e de germinação para avaliar a eficiência da inoculação e a influência do patógeno na germinação das sementes. Os testes foram conduzidos em delineamento inteiramente casualizado com quatro repetições de 25 sementes por placa, totalizando 200 sementes por tratamento.

\section{Progresso da ramulose no campo e avaliação da produção}

As avaliações da intensidade da doença foram iniciadas aos 46 dias após a semeadura (DAS), com 
intervalo de sete dias até a sexta avaliação e com intervalo de 15 dias na sétima e oitava avaliações. Avaliou-se a área útil da parcela, em um total de 80 plantas, desprezandose $0,5 \mathrm{~m}$ das extremidades. Em cada avaliação foram determinadas a incidência, dada em porcentagem de plantas sintomáticas, e a severidade da ramulose, obtida por meio da escala de notas elaborada por Costa (1941), em que, 0 = ausência de sintomas; $1=$ lesões necróticas estreladas nas folhas localizadas no ápice da planta; 2 = encurtamento dos internódios do ápice da planta; $3=$ superbrotamento acentuado, redução no crescimento da planta; 4 = planta com superbrotamento e com desenvolvimento comprometido, morte das partes afetadas. Aplicou-se o índice de Mckinney (1923) para ponderar a severidade na parcela.

A área abaixo da curva de progresso da doença (AACPD) foi obtida com base nos índices de incidência e de severidade, de acordo com Campbell \& Madden (1990). Os tratamentos foram comparados utilizando-se a área abaixo da curva de progresso da incidência (AACPI) e da severidade (AACPS) da ramulose.

Para a análise da produção foram colhidos $4 \mathrm{~m}$ da área útil de cada parcela, descartando-se $30 \mathrm{~cm}$ de cada lado. A produtividade $(\mathrm{kg} / \mathrm{ha}$ ) foi obtida a partir do peso do algodão em caroço colhido da área útil.

\section{Análise dos dados}

As análises foram realizadas com o auxílio do programa Sisvar. Equações de regressão foram ajustadas aos dados das variáveis quantitativas analisadas quando verificados efeitos significativos $(\mathrm{P} \leq 0,05)$.

\section{RESULTADOS E DISCUSSÃO}

No teste de germinação as sementes apresentaram $99 \%$ de germinação. Após a análise do perfil sanitário das sementes constatou-se a presença de Aspergillus spp. (1\%), Penicillium spp. (0,5\%) e Fusarium spp. (4\%).

\section{Inoculação e análise das sementes}

Houve diferença significativa para a incidência de C. gossypii var. cephalosporioides nas sementes de algodoeiro em função do tempo de exposição ao patógeno, observando-se aumento da incidência do fungo nas sementes com o aumento do tempo de exposição (Figura 1A). O método de inoculação por restrição hídrica foi eficiente e permitiu obter sementes infectadas (em torno de $60 \%$ ) no menor tempo de exposição ao patógeno (36 h), aumentando até atingir o ponto de máxima infecção (99,7\%) com $94 \mathrm{~h}$ de exposição das sementes ao patógeno. Resultados semelhantes foram obtidos por Araújo et al. (2006a), os quais, trabalhando com o mesmo patossistema e os tempos de inoculação de $0,36,72$ e 108 h, observaram maior incidência quando se aumentou o tempo de exposição das sementes a C. gossypii var. cephalosporioides. Essa eficiência também foi comprovada por Costa et al. (2003) em sementes de feijão inoculadas com Fusarium oxysporum
Schlechtend Fr. f. sp. phaseoli Kendrick \& Snyder nos tempos de $0,36,72,108$ e $144 \mathrm{~h}$, quando a incidência do patógeno foi maior com o aumento do tempo de exposição das sementes, sendo observados valores de 24,39 e 70,06\% para o menor e o maior tempo, respectivamente.

No teste de germinação das sementes, realizado após a inoculação com C. gossypii var. cephalosporioides, houve diferença significativa entre os diferentes tempos de exposição ao patógeno. Observou-se a redução na percentagem de germinação das sementes conforme o aumento do tempo de exposição ao patógeno. A menor germinação (92\%) foi observada para o tempo de $108 \mathrm{~h}$ de exposição das sementes ao patógeno e a máxima germinação $(99,5 \%)$ com $34 \mathrm{~h}$ de exposição das sementes ao patógeno (Figura 1B).

De acordo com Tanaka (1994) e Machado \& Pozza (2005), patógenos associados às sementes podem reduzir a porcentagem de germinação, além de serem grandes causadores de morte em pré e pós-emergência de plântulas. Considerando o patossistema estudado no presente trabalho, os resultados corroboram os observados por Araújo et al. (2006a), evidenciando-se a redução da germinação de sementes de algodoeiro inoculadas com C. gossypii var. cephalosporioides, sendo este decréscimo destacado no maior tempo $(108$ h) de exposição ao patógeno. Em
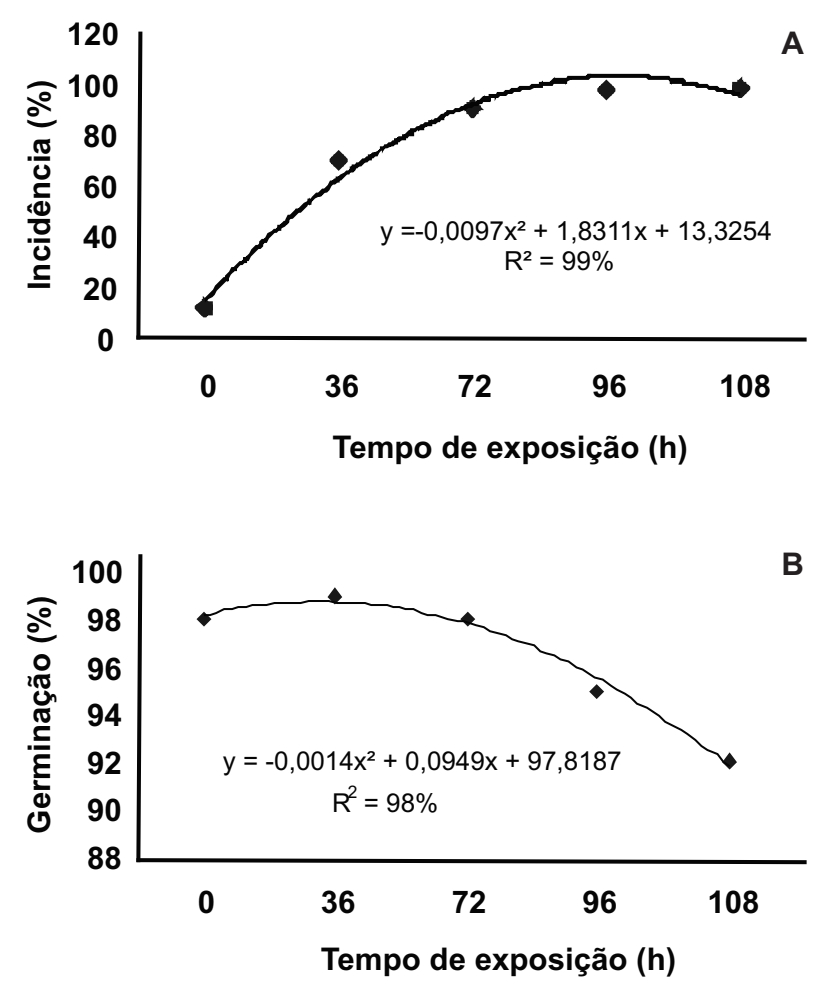

FIGURA 1 - A. Incidência de Colletotrichum gossypii var. cephalosporioides na semente; B. Germinação de sementes de algodoeiro em função do tempo de exposição das sementes ao patógeno. 
outros patossistemas também se observou a influência dos patógenos estudados na qualidade da semente inoculada. Considerando o trabalho realizado por Costa et al. (2003), foi observada a redução na germinação de sementes de feijão inoculadas com $F$. oxysporum f. sp. phaseoli quando o período de inoculação aumentou de zero até $144 \mathrm{~h}$. Resultados semelhantes foram observados por Sousa et al. (2008) com F. oxysporum f. sp. vasinfecutm W.C. Snyder \& H.N. Hansen, quando a redução na germinação foi atribuída à presença do patógeno inoculado nas sementes de algodoeiro, independente do método de inoculação utilizado.

\section{Progresso da ramulose no campo e avaliação da produção}

Durante o período de avaliação da doença, a temperatura variou entre 19,2 e $32,6^{\circ} \mathrm{C}$, com média de $24,8^{\circ} \mathrm{C}$. A precipitação e a umidade relativa apresentaram valores médios de $235 \mathrm{~mm}$ e 84,2\%, respectivamente. Segundo Kimati et al. (2005), a temperatura ótima para a infecção por C. gossypii var. cephalosporioides no campo é próxima de $22^{\circ} \mathrm{C}$, além de alta umidade relativa do ar. As condições ambientais observadas no período de avaliação de incidência e severidade se mostraram favoráveis para a ramulose, resultando em aumento da doença ao longo do período de avaliação. Em trabalho realizado por Santos et al. (1994), sobre o progresso e o gradiente da ramulose do algodoeiro, foi constatado que, em condições de alta temperatura e alta umidade relativa, a doença progrediu 1,0 m no espaço, a cada cinco dias, a partir da fonte de inóculo inicial. Da mesma forma, Araújo et al. (2009), trabalhando com níveis de fonte de inóculo inicial $(0 ; 0,1$; 0,$2 ; 0,4 ; 0,8$ e 1,2\% de plantas inoculadas e sintomáticas), em 2006 e 2007, descreveram que as condições ambientais foram determinantes para a alta correlação $(0,82)$ entre a incidência da ramulose, quando $70 \%$ das maçãs de algodoeiro estavam formadas, e a incidência de C. gossypii var. cephalosporioides nas sementes, no ano de 2006. Segundo os autores, neste ano houve maior distribuição de chuvas ao longo do ciclo da cultura, o que favoreceu a dispersão do inóculo no período de formação de maçãs.

Avaliando a ramulose a partir dos 46 DAS, observouse diferença significativa entre os tratamentos quanto à incidência (AACPI) e a severidade (AACPS) da ramulose nas plantas de algodoeiro. Ao comparar os diferentes tempos de exposição das sementes ao patógeno, a AACPI e a AACPS foram maiores conforme aumentou o tempo de exposição (Figura 2). Apesar de a porcentagem de sementes inoculadas ter sido igual em todos os tratamentos (5\%), o progresso da doença foi maior de acordo com a quantidade de inóculo nas sementes proporcionado pelo tempo em que as sementes ficaram em contato com o patógeno durante a inoculação, sendo ainda favorecido pelas condições ambientais registradas no período de avaliação da doença, conforme mencionado anteriormente. Estes resultados sugerem que as plantas provenientes de sementes infectadas
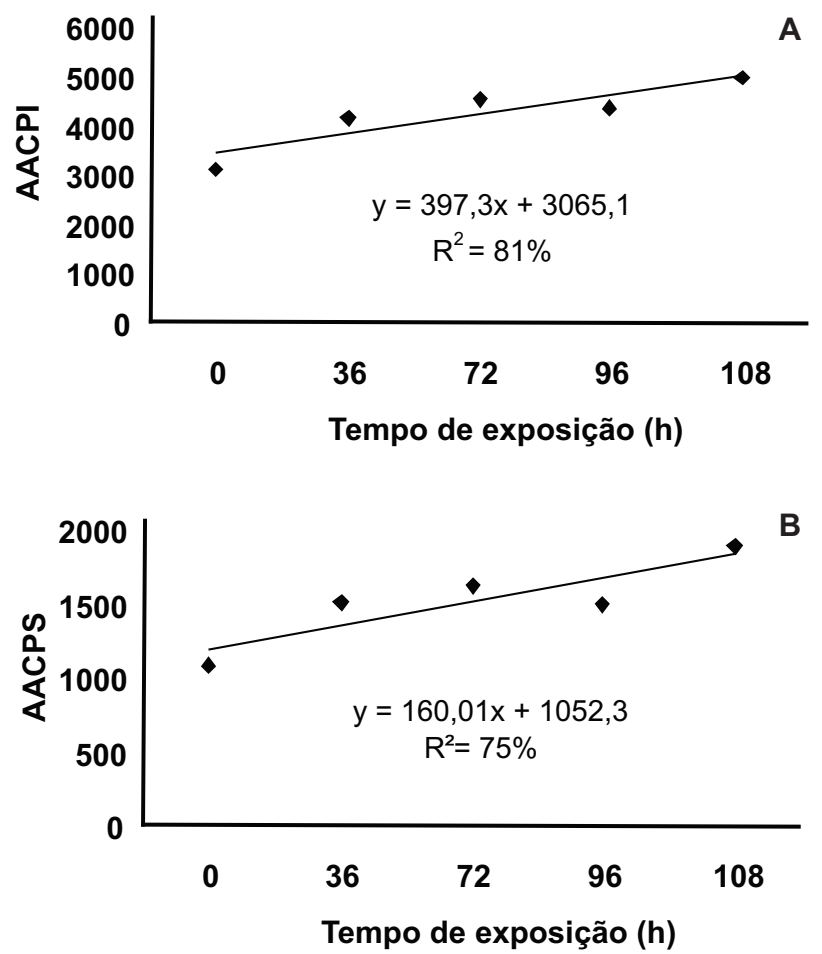

FIGURA 2 - A. Área abaixo da curva de progresso da incidência (AACPI) e B. da severidade (AACPS) em função do tempo de exposição das sementes a Colletotrichum gossypii var. cephalosporioides.

favoreceram a contaminação das plantas adjacentes. Essas plantas por sua vez, teriam servido como fonte de inóculo secundário para as demais plantas da parcela, contribuindo para o aumento do progresso da doença no tempo e no espaço. Estes resultados estão de acordo com os obtidos por Santos et al. (1994), os quais observaram aumento da doença a partir da fonte de inóculo inicial em condições ambientais favoráveis.

Semelhantemente, Araújo et al. (2006b), trabalhando com níveis de 0 a $16 \%$ de sementes de algodoeiro inoculadas com C. gossypii var. cephalosporioides, observaram o aumento na AACPI e AACPS diretamente proporcional ao nível de inóculo inicial do patógeno nas sementes. Em outro experimento, Pizzinatto et al. (1991), utilizando sementes de algodoeiro provenientes de plantas com notas de severidade da ramulose variando de 1 a 5 , observaram maior porcentagem de plantas doentes no tratamento em que se utilizaram sementes de plantas com maior severidade da doença. Semelhantemente ao observado com o patossistema em estudo, Sousa et al. (2008), em experimento com $F$. oxysporum f. sp. vasinfectum em sementes de algodoeiro, observaram que a severidade da murcha de fusarium foi maior com o aumento do período de exposição das sementes ao patógeno, para os três métodos de inoculação testados, os quais tiveram a restrição hídrica como base. 
A maior intensidade da doença foi observada aos 111 DAS em todos os tratamentos, alcançando valores de 92,1 e $42,5 \%$ no tempo de 108 h para a incidência e a severidade, respectivamente. $\mathrm{O}$ tempo $0 \mathrm{~h}$ de exposição, que correspondeu à testemunha, mantevese com valores de incidência e severidade menores que os demais tratamentos durante todo o período de avaliação, alcançando os maiores valores também aos 111 DAS (Figura 3). Observou-se, portanto, que o nível de inóculo, proporcionado pelo tempo de exposição das sementes ao patógeno, mesmo em baixa quantidade de sementes infectadas levadas ao campo (5\%), resultou em progresso considerável da doença nas condições ambientais em que o experimento foi conduzido. Essas observações poderão ser utilizadas como suporte para a determinação de padrões de tolerância do patógeno nas sementes destinadas ao plantio.

Ressalta-se que C. gossypii var. cephalosporioides é um patógeno que se dissemina de forma eficiente pelo vento e impacto de gotas de chuva; portanto, a ocorrência de sintomas de ramulose nas parcelas testemunhas pode ser considerada como contaminação secundária proveniente das parcelas inoculadas. Esses resultados reproduzem os descritos por Araújo et al. (1996b), em que a testemunha,
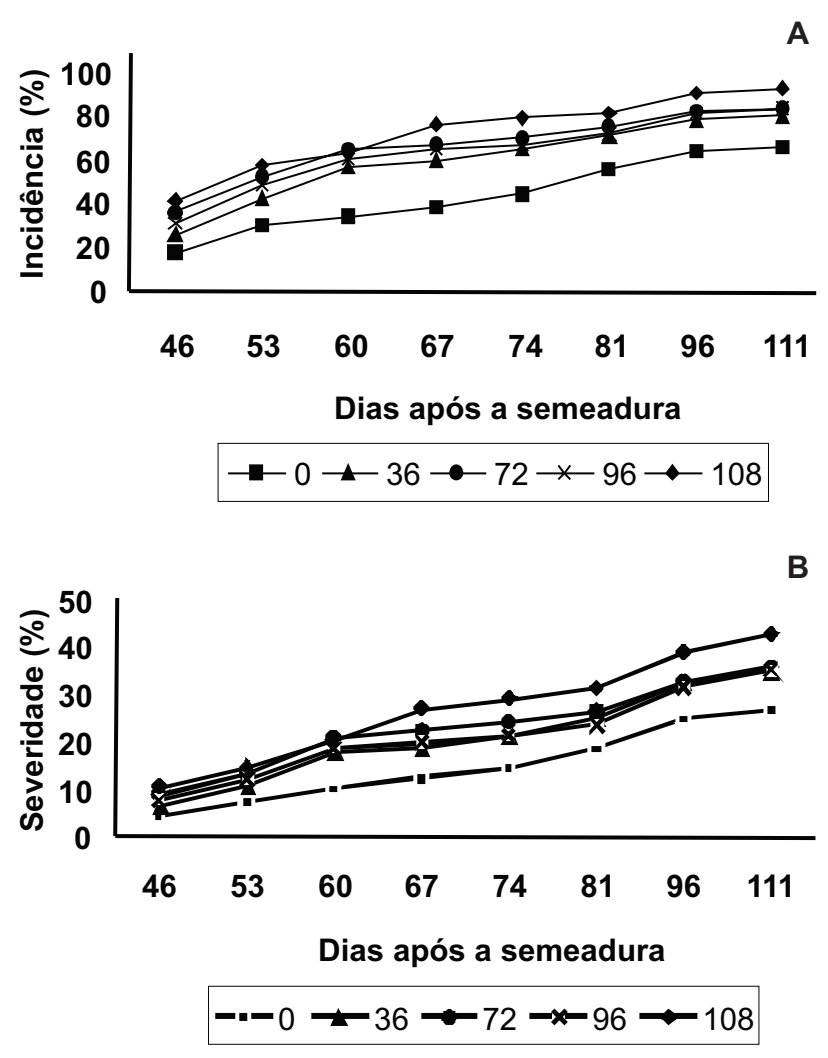

FIGURA 3 - A. Curva de progresso da incidência e B. da severidade da ramulose em plantas de algodoeiro avaliadas dos 46 aos 111 dias após a semeadura. sem sementes inoculadas, também apresentou sintomas da doença no campo.

A diferença na intensidade da doença no campo não proporcionou diferença significativa entre os tratamentos quanto à produção de algodão em caroço. Da mesma forma, Araújo et al. (2006b), ao analisarem diferentes níveis de inóculo inicial de C. gossypii var. cephalosporioides nas sementes, não observaram diferença na produção de algodão em caroço.

A inoculação, utilizando diferentes tempos de exposição das sementes ao fungo, simula a infecção natural de sementes, pois sementes naturalmente infectadas podem apresentar quantidade de inóculo diferente e, com isso, favorecer diferentemente o aumento da ramulose no campo, dependendo das condições ambientais. Portanto, a análise do progresso da doença em função do nível de inóculo nas sementes gera informação útil para o manejo da doença.

Os resultados obtidos neste trabalho são de grande importância para o estudo do progresso da ramulose nas condições de campo. O método de inoculação das sementes com o uso da técnica da restrição hídrica permitiu a obtenção de sementes com quantidade diferente de inóculo do patógeno, o que possibilitou estudar o progresso da doença no estado de Mato Grosso a partir de sementes com infecção diferenciada, simulando a infecção natural de sementes produzidas em campo.

\section{AGRADECIMENTOS}

Os autores agradecem à Fundação Mato Grosso, pelo fornecimento do isolado de Colletotrichum gossypii var. cephalosporioides e das sementes utilizadas neste estudo.

\section{REFERÊNCIAS BIBLIOGRÁFICAS}

Alves MC, Pozza EA, Machado JC, Araújo DV, Talamini V, Oliveira MS (2006) Geoestatística como metodologia para estudar a dinâmica espaço-temporal de doenças associadas a Colletotrichum spp. transmitidas por sementes. Fitopatologia Brasileira 31:557-563.

Araújo AE, Menten JOM, Ferreira ACB, Dias CTS, Nóbrega MBM, Morello CL (2009) Efeito de diferentes níveis de Colletotrichum gossypii South var. cephalosporioides Costa, em plantas de algodão no campo e sua incidência nas sementes. Summa Phytopathologica 35: 310-315.

Araújo DV, Pozza EA, Machado JC, Zambenedetti EB, Celano FAO, Carvalho EM, Camargos VN (2006a). Influência da temperatura e do tempo de inoculação das sementes de algodão na transmissibilidade de Colletotrichum gossypii var. cephalosporioides. Fitopatologia Brasileira 31:35-40.

Araújo DV, Pozza EA, Machado JC, Zambenedetti EB, Carvalho EM, Celano FAO (2006b). Relação entre níveis de inóculo de Colletotrichum gossypii var. cephalosporioides nas sementes e o progresso da ramulose do algodoeiro. Fitopatologia Brasileira $31: 147-151$

Bergamin Filho A, Hau B, Amorim L, Jesus Junior WC (2004) 
Análise espacial de epidemias. In: Vale, FXR, Jesus Junior, WC, Zambolim, L. (Eds.) Epidemiologia aplicada ao manejo de doenças de plantas. Belo Horizonte MG. Editora Perfil. pp. 193-240.

Campbell CL, Madden LV (1990) Introduction to plant disease epidemiology. New York NY. John Willey \& Sons.

Costa MLN, Machado JC, Guimarães RM, Guimarães RM, Pozza EA, Oride D (2003) Inoculação de Fusarium oxysporum f. sp. phaseoli em sementes de feijoeiro através de restrição hídrica. Ciência e Agrotecnologia 27:1023-1030.

Costa AS (1941) Investigação sobre a ramulose. Campinas SP. Instituto Agronômico de Campinas - Seção de Algodão (Relatório no. 1012).

Kimati H, Amorim L, Rezende JAM, Bergamin Filho A, Camargo LEA (Eds.) (2005) Manual de Fitopatologia. Vol. 2. Doenças das Plantas Cultivadas. $4^{\mathrm{a}}$. Ed. São Paulo SP. Ceres.

Machado JC, Oliveira JA, Vieira MGGC, Alves MC (2004) Uso da restrição hídrica na inoculação de fungos em sementes de algodoeiro (Gossypium hirsutum L.). Revista Brasileira de Sementes 26:62-67.

Machado JC, Pozza EA (2005) Razões e procedimentos para o estabelecimento de padrões de tolerância a patógenos em sementes. In: Zambolim L (Ed.) Sementes: Qualidade fitossanitária. Viçosa MG. UFV. pp. 375-398.

Machado AQ, Machado JC, Vieira MDGGC, Cassetari Neto D, Souza MV (2007) Potencial do uso da restrição hídrica em testes de sanidade de sementes de algodoeiro. Fitopatologia Brasileira 32:408-414.

McKinney HH (1923) Influence of soil temperature and moisture on infection of wheat seedlings by Helminthosporium sativum. Journal of Agricultural Research 26:195-219.

Michel BE, Radcliffe D (1995) A computer program relating solute potential to solution composition for five solutes. Agronomy Journal 87:131-136.

Ministério da Agricultura, Pecuária e Abastecimento (2009) Regras para Análise de Sementes. Brasília DF. MAPA/ACS.

Pizzinatto MA, Cia E, Fuzatto MG (1991) Transmissão de Colletotrichum gossypii var. cephalosporioides por sementes de algodoeiro. Summa Phytopathologica 17:207-217.

Santos GR, Zambolim L, Vale FXR, Vieira JM (1994) Progresso e gradiente da ramulose do algodoeiro. Fitopatologia Brasileira 19:390-393.

Sousa MV, Machado JC, Pfenning LH, Kawasaki VH, Araújo DV, Silva AA, Martini Neto A (2008) Métodos de inoculação e efeitos de Fusarium oxysporum f. sp. vasinfectum em sementes de algodoeiro. Tropical Plant Pathology 33:41-48.

Tanaka MAS (1994) Patógenos causadores de tombamento do algodoeiro e seus efeitos sobre a germinação das sementes em diferentes temperaturas. Fitopatologia Brasileira 19:29-33.

Tanaka MAS, Menten JOM (1992) Relação entre a resistência do algodoeiro à ramulose e a transmissão de Colletotrichum gossypii var. cephalosporioides pelas sementes. Summa Phytopathologica 18:227-234.

Tanaka MAS, Menten JOM, Marianno MIA (1989) Inoculação artificial de sementes de algodão com Colletotrichum gossypii var. cephalosporioides e infecção das sementes em função do tempo de exposição ao patógeno. Summa Phytopathologica 15:232-237.

TPP 65 - Recebido 21 Março 2011 - Aceito 5 Abril 2012

Editor de Seção: José Maurício Fernandes 